SHORT REPORT

\title{
Use of tissue adhesives in sport? A new application in international ice hockey
}

\section{A S Branfield}

Br J Sports Med 2004;38:95-96. doi: 10.1136/bjsm.2002.004028

In the tough, competitive environment of international ice hockey, it is vital that a player who sustains a minor facial laceration is returned to play as soon as possible. A method of wound closure that is fast to apply, water resistant, and effective was sought. Dermabond, a cyanoacrylate tissue adhesive, was selected for use during the 2002 International Ice Hockey Federation World Championships for the closure of selected facial wounds. The wounds were all closed using prescribed aseptic techniques. The results are presented and discussed. The tissue adhesive met the criteria set out.

ce hockey has been described as a "collision and not a contact sport" (commentator remarks, Salt Lake City 2002 Winter Olympic Games). Player contact with other players or with the boards, often at high speed, contributes to the risk of injury. A steady increase in injury rates has been shown with an increase in player age and level of play. Injury rates have been recorded in the Finnish National League ( 83 per 1000 player hours $)^{1}$ and in the US Hockey League (under 20) (96 per 1000 player hours). ${ }^{2}$

Stuart and Smith, ${ }^{2}$ in the 1990s, found that the most common injury was the facial laceration. However, in a study conducted in Finland, Molsa et al ${ }^{1}$ concluded that the decreasing trend in the proportion of facial lacerations and injuries may be explained by the more common use of a face visor. Despite this decreasing incidence, lacerations are still the third most common type of injury cited by Molsa after contusion and sprain/strain. Lacerations are more likely to occur on exposed areas, especially the facial region, and can occur when a face protector is worn.

Ice hockey is played at a fast pace with frequent line changes, so a return to action as soon as possible for a player after sustaining a minor injury is vital. The players, however, play hard and are encumbered with bulky uniforms/ protective gear. The players sweat profusely, making the skin surface wet. The combination of speed, collision, hard surfaces, and moisture make for a challenging playing environment with a high injury potential.

\section{MATERIALS AND METHODS}

The senior men's teams representing six countries (Australia, Belgium, Estonia, Israel, South Africa, and Turkey) competed in the International Ice Hockey Federation (IIHF) Division II Group A World Championships held in Cape Town, South Africa from 31 March to 6 April 2002. Fifteen games were played, each comprising three periods of 20 minutes (900 minutes of actual playing time). All games were attended by the host medical officer. Lacerations for study were selected using the following criteria:

- facial distribution

- less than $10 \mathrm{~cm}$ in length
- linear (not jagged or stellate)

- no involvement of mucus membranes

- could be closed in a single layer (subcutaneous sutures not required)

- haemostasis could be easily achieved

- no infection

- no head injury (concussion present)

Details of the injury, such as mechanism, area of play, period of play, and whether the player returned to the ice, were also recorded. All injuries were reported on the standard IIHF injury report form and were submitted to the tournament medical supervisor, Dr Mark Aubry (Canada).

All selected lacerations were repaired by the host medical officer in an aseptic prescribed manner. All patients were removed from the ice and examined under good light conditions in the first aid room. No topical anaesthetic was required. Wounds were cleaned with sterile water. The wound edges were opposed. The Dermabond vial was crushed and inverted. The adhesive was gently brushed over the laceration. No adhesive was pushed into the wound. Three layers of adhesive were applied to ensure optimal strength to the wound closure. The adhesive was allowed to dry for three minutes. The player was then allowed to return to his team. All wounds were reassessed on alternate days during the tournament.

Dermabond is a cyanoacrylate tissue adhesive which forms a strong bond across opposed wound edges, allowing normal healing to occur below. It is marketed to replace sutures that are 5-0 or smaller in diameter for incision or laceration repair. This adhesive has been shown to save time during wound repair, providing a flexible, water resistant protective coating and eliminating the need for suture removal. It was selected as the repair method for the study. ${ }^{3}$ The adhesive is relatively easy to use after appropriate wound preparation. No local anaesthetic is necessary. No suture tray or sterile instruments are required.

In a study on lacerations randomly assigned to receive suturing or octylcyanoacrylate tissue adhesive, both groups had similar healing but the tissue adhesive group took about one quarter as much time as suturing . ${ }^{4}$

\section{RESULTS}

Six facial lacerations occurred during the tournament. Two were excluded from the study. Sites involved were the right eyebrow (one), left eyebrow (two), and right upper eyelid (one). Wound length ranged from 2 to $8 \mathrm{~cm}$. Mechanisms of injury were high sticking (two), contact with the boards (one), and contact with the puck (one). Two injuries were caused by foul play. By nationality, patients treated were South African (two), Australian (one), and Belgian (one). The excluded patients were Turkish (one) and Estonian 
(one). All players were removed from the ice and examined by the host medical officer. The four included lacerations were cleaned and repaired using the recommended sterile technique for Dermabond. The repair was carried out under good light conditions in the first aid room.

Three players returned immediately to the field of play. One player sustained his injury at the end of the match. All wounds were followed up on a daily basis during the duration of the tournament. No infections occurred. All wounds healed rapidly and without complications and had an acceptable cosmetic appearance (to both patient and doctor).

\section{DISCUSSION}

During a highly competitive international ice hockey tournament, few facial injuries occurred, resulting in a small study of only four facial lacerations that met the inclusion criteria. Although ice hockey is a moist environment, the wounds remained intact. Despite face visor protection, two of the players included sustained facial injuries wearing half visors. The adhesive was quick to apply (in all four cases less than five minutes), with three of the players being able to return to the ice within 15 minutes of sustaining the injury.

The adhesive acts as its own water resistant bandage, and no added covering was needed. Patients were able to shower normally. Dermabond tissue adhesive offers a fast, painless method of wound closure that results in strongly bonded water resistant wounds. The advantages of tissue adhesive are:

(1) Maximum bonding strength at two and a half minutes

(2) Equivalent in strength to healed tissue at seven days after repair

(3) Can be applied using no anaesthetic and no needles!

(4) Faster repair time

(5) Better acceptance by patients

(6) Water resistant covering

(7) Removal of sutures not required, so no follow up consultation
(8) Requires minimal surgical equipment and can be done outside of theatre in less than ideal light

\section{Author's affiliation}

A S Branfield, PO Box 1770, Randpark Ridge, Randburg 2156, South Africa; Andy.branfield@medicross.co.za

Accepted 20 May 2003

\section{REFERENCES}

1 Molsa J, Kujala U, Nasman O, et al. Injury profile in ice hockey from the 1970s through the 1990s in Finland. Am J Sports Med 2000;28:322-7.

2 Stuart MJ, Smith A. Injuries in junior A ice hockey. A three year prospective study. Am J Sports Med 1995;23:458-61.

3 Bruns TB, Worthington JM. Using tissue adhesives for Wound Repair: A practical guide to Dermabond. Am Fam Physician 2000;61:1383.

4 Quinn J, Wells G, Sutcliffe T, et al. A randomized trial comparing octylcyanoacrylate tissue adhesive and sutures in the management of laceration. JAMA 1997;277:1527-30.

\section{COMMENTARY}

This report highlights an alternative method of repairing lacerations. It is less invasive than suturing and does not require anaesthesia. As stated, it takes less time for wound repair and the player can return to play without delay. The use of a tissue adhesive such as octylcyanoacrylate is especially effective in superficial lacerations around the eye and mouth areas. Unfortunately in ice hockey, most lacerations are deep and jagged and require the use of sutures for repair. The use of suturing versus a tissue adhesive in the closure of lacerations would also vary depending on the experience of the doctor and his/her preference for one method over the other. In conclusion, tissue adhesive such as octylcyanoacrylate can be used effectively in certain small superficial lacerations of the facial area with great success.

M Aubry Chief Medical Office of the International Ice Hockey Federation, Brandschenkestrasse 50, Zurich 8002, Switzerland markaubry@rogers.com 